\title{
Testicular function and fertility in bulls
}

\author{
John P. Kastelic ${ }^{1}$ and Jacob Thundathil ${ }^{2}$ \\ Department of Production Animal Health, University of Calgary, Faculty of Veterinary Medicine, 3330 \\ Hospital Drive NW, Calgary, AB, Canada T2N 4NT
}

\begin{abstract}
Summary
Since one bull may be responsible for impregnating numerous cows, testicular function and fertility are of critical importance. Within this broad context, this review will focus on: the effects of nutrition on reproductive development; scrotal/testicular thermoregulation; breeding soundness; and sperm function/fertility. Bulls fed above-maintenance levels of energy and protein before $30 \mathrm{wk}$ of age had increased luteinizing hormone pulse frequency, hastened puberty, and increased testicular size at maturity (compared to those that were underfed during this interval). However, after $30 \mathrm{wk}$ of age, supplemental nutrition generally did not improve reproductive potential (but sometimes decreased it). There are several mechanisms (including blood vessels) that maintain a bull's testes 2 to $6{ }^{\circ} \mathrm{C}$ cooler than core body temperature for production of fertile sperm (increased testicular temperature reduces semen quality). Although fertility varies substantially among bulls, it is generally easier to identify bulls with low fertility than to accurately distinguish among bulls with good to excellent fertility. Compensable sperm abnormalities can be overcome by increasing the number of sperm used for artificial insemination; these abnormalities are attributed to sperm failing to reach and penetrate the zona pellucida. In contrast, increasing the insemination dose will not improve fertility for uncompensable defects, implying that these sperm are able to cause fertilization and initiate development, but they do not sustain embryogenesis.
\end{abstract}

\section{Introduction}

Fertility is much more important in any individual bull than an individual cow, since one bull may be responsible for breeding up to 40 females or perhaps thousands (natural service and artificial insemination, respectively). In a recent review (Flowers 2013), it was concluded that beef bulls make a substantial contribution to infertility, whereas in dairy cattle, infertility was attributed more to the cow than the bull. Furthermore, of all the assisted reproductive technologies developed for cattle, none is more important than artificial insemination (Al; 
Rodriguez-Martínez 2012). Consequently, a clear understanding of testicular function and fertility in bulls is of critical importance. Within this very broad topic, this review highlights selected aspects of the effects of nutrition on reproductive development, scrotal/testicular thermoregulation, breeding soundness, and prediction of fertility (the latter topic is primarily work published in the last $5 \mathrm{y}$ ).

\section{Effects of bull nutrition on testicular development and function}

There is good evidence that early-life nutrition affects reproductive development and function in bulls. In an older study (Bratton et al. 1959), Holstein bulls were fed low, adequate or high nutrition (approximately 60,100 , or $160 \%$ of recommended amounts of total digestible nutrients, respectively) from 1 to 80 wk of age. In that study, bulls fed low nutrition had delayed puberty, smaller testes, and reduced sperm production compared to those fed high nutrition. In another older study in beef bulls, yearling scrotal circumference increased with increasing age of the dam (up to 5 to 9 y of age); bulls raised by 2 -y-old dams had a scrotal circumference 0.7 to $1.3 \mathrm{~cm}$ smaller than bulls raised by dams that were 5- to 9-y-old (Lunstra et al. 1988), presumably due to greater milk production by older dams.

More recently, four experiments were conducted to evaluate the effects of nutrition during calfhood (10 to 26-30 wk of age) and the peripubertal period (27-31 to 70-74 wk) on sexual development and reproductive function in beef bulls (reviewed by Barth et al. 2008). Overall, high nutrition during calfhood increased LH pulse frequency during the early gonadotropin rise (approximately 6 to $25 \mathrm{wk}$ of age), hastened puberty and resulted in larger testes and larger epididymal sperm reserves at sexual maturity. In contrast, low nutrition during calfhood had the opposite effects. For example, for bulls fed low-, medium- or high-nutrition diets from 10 to $70 \mathrm{wk}$, age at puberty was (mean \pm SEM) $326.9 \pm 5.5,304.7 \pm 7.4$, and $292.3 \pm 4.6 \mathrm{~d}$ respectively, and paired testis weights were $523.9 \pm 25.8,552.4 \pm 21.1$, and $655.2 \pm 21.2$ g. It was noteworthy that in bulls fed low nutrition prior to approximately $26 \mathrm{wk}$ of age, and subsequently fed high nutrition, suppression of testicular development and delayed puberty were not overcome. Therefore, it was not possible to retrospectively compensate for the effects of low nutrition early in life.

Post-weaning nutrition can also affect reproduction in bulls. In a series of experiments, Angus, Hereford, and Simmental bulls were fed high (80\% grain and $20 \%$ forage) or medium nutrition from weaning ( $\sim 6-7 \mathrm{mo}$ ) to 12-24 mo of age (summarized in Coulter \& Kastelic 1999). Although bulls receiving high nutrition had greater body weight and back fat, paired testis weight was not affected. It was noteworthy that bulls receiving high nutrition had lower daily sperm production and epididymal sperm reserves, and a higher percentage of morphologically abnormal sperm. Perhaps increased dietary energy adversely affected sperm production and semen quality due to fat deposition in the scrotum, thereby reducing heat radiated from the scrotal skin, and increasing scrotal and testicular temperatures. Therefore, for optimal reproductive development and function, beef bulls should be fed to achieve average daily gains of approximately 1.0 to $1.6 \mathrm{~kg} / \mathrm{d}$ prior to 6 mo of age, and then fed a balanced diet to achieve more moderate weight gains, without becoming excessively fat (Brito et al. 2012).

\section{Testicular temperature}

It is well known that a bull's testes must be cooler $\left(\sim 2\right.$ to $\left.6{ }^{\circ} \mathrm{C}\right)$ than core temperature for production of fertile sperm. Consequently, increased testicular temperature (regardless of the 
underlying cause) reduces semen quality, and is frequently suspected as the underlying cause of bull infertility (Kastelic 2014). Several features contribute to keeping testes cool, including thin scrotal skin, scrotal/testicular vasculature, and a distinct scrotal neck. The 'testicular vascular cone' (Cook et al. 1994), which is located immediately above the testis, is comprised of the highly coiled testicular artery surrounded by the venous pampiniform plexus; collectively, this functions as a classical counter-current heat exchanger, transferring heat from the artery to the vein. In addition, sweating and panting increase heat loss and decrease testicular temperature.

Scrotal and testicular temperatures, and the apparent roles of blood vessels in achieving these temperatures, have been described. Top to bottom differences (gradients) in temperature were 1.6, 0.4 and $-0.2{ }^{\circ} \mathrm{C}$ for scrotal surface, scrotal subcutaneous and intratesticular temperatures, respectively (Kastelic et al. 1995). Therefore, moving from top to bottom, the scrotum gets cooler, whereas the testis (when they are experimentally removed from the scrotum), get warmer. These temperature gradients are consistent with their vasculature. The scrotum is apparently vascularized from top to bottom. In contrast, the testis is essentially vascularized from the bottom to the top; the testicular artery exits the bottom of the testicular vascular cone, courses the length of the testis, and at the bottom of the testis, divides into multiple branches that spread upwards and sideways across the surface of the testis before entering the testicular parenchyma (Kastelic et al. 1996, Kastelic et al. 1997; Fig. 1). Blood within the testicular artery has a similar temperature at the top of the testis compared to the bottom of the testis, but there is a significant decrease in intra-arterial temperature between the bottom of the testis and the point of entry into the testicular parenchyma. Therefore, both the scrotum and the testis are warmest at the origin of their blood supply (top of scrotum and bottom of testis), and they get cooler distal to that point (bottom of scrotum, top of testis; Kastelic et al. 1996, Kastelic et al.

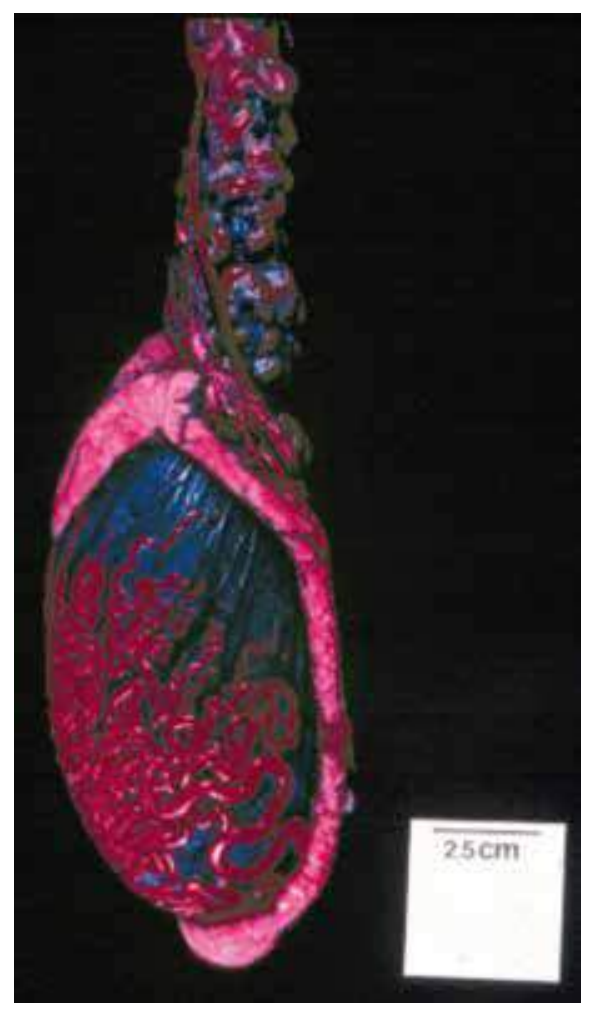

Fig. 1. Vascular cast of the spermatic cord, testis, epididymis and in a 2-y old beef bull. The cast was prepared by flushing the testicular artery and vein, and injecting them with red and blue latex, respectively, allowing latex to harden, and placing the structure in sodium hydroxide (to digest the tissues and liberate the cast). The testicular vascular cone, consisting of the coiled testicular artery surrounded by the venous pampiniform plexus, is above the testis. Note that the testicular artery exits the bottom of the testicular vascular cone, passes to the bottom of the testis (underneath the corpus epididymis), and then is readily visible on the posterior surface of the testis, as it branches and spreads upwards, before entering the testicular parenchyma.

Previously published* and used with permission.

*Kastelic JP. Understanding and evaluating bovine testes. Theriogenology 2014;81:18-23. 
1997). Collectively, these opposing temperature gradients collectively result in a nearly uniform intratesticular temperature in situ.

\section{Sources of testicular heat}

Testicular blood flow and oxygen uptake were measured in eight Angus bulls to determine relative contributions of blood flow and metabolism as sources of testicular heat (Barros et al. 1999). Blood flow in the testicular artery averaged $12.4 \mathrm{~mL} / \mathrm{min}$. Arterial blood was warmer (39.2 versus $\left.36.9^{\circ} \mathrm{C}, \mathrm{P}<0.001\right)$ and had more oxygen-saturated hemoglobin $(95.3$ versus $42.0 \%$ $\mathrm{P}<0.001$ ) than blood in the testicular vein. Based on blood flow and hemoglobin saturation, the oxygen used by one testis $(1.2 \mathrm{~mL} / \mathrm{min})$ was calculated to produce 5.8 calories of heat/ min, compared to 28.3 calories/min dissipated in the testes by blood (based on flow rate and relative temperatures of arterial and venous blood). Therefore, the major source of testicular heat was blood flow, not metabolism (Barros et al. 1999).

\section{Pathogenesis of heat-induced changes in sperm morphology}

The testis is close to hypoxia under physiological conditions (Kastelic 2014); consequently, when scrotal/testicular temperatures increase, metabolism and oxygen consumption concurrently increase, but blood flow to the testis is largely unaffected, and the testis becomes hypoxic (Kastelic 2014). Although this has been the long-standing dogma regarding the cause of heatinduced changes in sperm morphology, remarkably, there is little or no experimental data to support this assertion. In a novel study, mice were subjected to ambient temperatures of 20 or $36{ }^{\circ} \mathrm{C}$ and concurrently exposed to hyperoxic conditions to prevent the hypoxia induced by elevated testicular temperature (Kastelic et al. 2008). In that study, hyperoxia (known to increase testicular oxygen saturation) did not protect against hyperthermia-induced deterioration in sperm quality. Furthermore, since sperm characteristics were not significantly different between mice exposed to hypoxic versus normoxic or hyperoxic conditions at $20{ }^{\circ} \mathrm{C}$, it appeared that the effects of increased testicular temperature on semen quality were due to hyperthermia per se and not hypoxia (Kastelic et al. 2008). Similar results were obtained with a scrotal insulation model in rams (Kastelic et al. unpublished). Although further work is needed to verify these findings, they do question the long-standing dogma that the effects of increased testicular temperature on sperm morphology are due to hypoxia.

\section{Breeding soundness evaluation}

Although 20 to $40 \%$ of bulls may have reduced fertility, few are completely sterile (Coulter \& Kastelic 1999). In general, reproductive potential of bulls can be determined by either: 1) breeding a large number of normal, fertile females and assessing pregnancy; or 2) conducting a breeding soundness evaluation. Although the former approach is the ultimate test of fertility, it is expensive, particularly if reproductive performance is poor. Consequently, it is strongly recommended to conduct a breeding soundness evaluation to identify and eliminate bulls expected to have poor fertility. Breeding soundness includes satisfactory general health, physical soundness, libido, and semen quality. The classification is based on physical evaluation (to ensure that a bull is healthy and free of structural defects) and the bull's ability to meet minimum 
standard for testicular development, sperm motility, and normal sperm morphology. Although adequate libido is essential for natural service, it is not routinely evaluated.

\section{Scrotal circumference}

Scrotal circumference, which is highly correlated with testis size, is an integral component of a breeding soundness evaluation (Kastelic \& Thundathil 2008, Kastelic et al. 2012). Since scrotal circumference increases with age, the minimum acceptable scrotal circumference is affected by the age of the bull (some indices also include breed-specific adjustments). In one study, breeding soundness evaluations were done on 3648 bulls; $76.2 \%$ were classified as satisfactory potential breeders, with $7.1 \%$ of all bulls deemed unsatisfactory on the basis of inadequate scrotal circumference (Kennedy et al. 2002). In another study (Higdon et al. 2000) which involved approximately 3000 yearling beef bulls, 10 to $13 \%$ of all bulls evaluated were deemed unsatisfactory (depending on the minimum standard used for scrotal circumference). In a Western Canadian study involving nearly 3000 beef bulls (Waldner et al. 2010), bulls with a scrotal circumference exceeding $34 \mathrm{~cm}$ had more $(P<0.006)$ morphologically normal sperm than bulls with a smaller scrotal circumference. In addition, bulls with a larger scrotal circumference got more cows pregnant $(\mathrm{P}<0.05)$ with a shorter median interval from bull exposure to calving $(\mathrm{P}<0.02)$.

\section{Compensable versus uncompensable sperm defects}

Although there are several systems of classifying sperm, designating them as compensable and un-compensable defects is a useful approach (reviewed in Amann \& DeJarnette 2012; this paragraph is based on that review). In that regard, increasing the number of sperm inseminated will overcome compensable abnormalities which are attributed to sperm viability and their propensity to reach and penetrate the zona pellucida (including motility, acrosome integrity, and cell membrane integrity). For example, sperm with a bent midpiece or a knobbed acrosome are unlikely to initiate fertilization. In contrast, increasing the insemination dose does not improve fertility for uncompensable defects. Apparently, these sperm are able to cause fertilization and initiate development, but are unable to sustain embryogenesis, with most failures occurring prior to Day 8. Examples of this defect include chromosomal abnormalities and protamine status, as these sperm are expected to initiate fertilization but not sustain development.

The 'threshold' in sperm numbers is the limit beyond which further increases in sperm numbers per insemination dose fail to improve fertility, which can be due to reaching the limit of female fertility, or a value below the level of female fertility, due to the presence of uncompensable sperm defects (Amann \& DeJarnette 2012). The threshold can vary among bulls or even ejaculates, depending on the nature and the proportion of compensable and uncompensable sperm defects. Bulls with increasing fertility in response to a wide range in insemination doses are considered to have primarily compensable sperm defects; in contrast, those that quickly reach a fertility 'plateau' are regarding as having primarily uncompensable sperm defects. Notwithstanding, most fertility curves reach their threshold when $70 \%$ of sperm have a compensable trait (Flowers 2013).

Compensable sperm quality attributes are those that affect the ability of a sperm to access and fertilize an ovum. Therefore, measurements of motility, viability, and membrane function are commonly used to estimate compensable sperm quality. However, given that they do not 
assess uncompensable semen traits, they are most appropriate to determine the number of sperm per insemination dose to reach maximal fertility rather to than predict absolute fertility (Amann \& DeJarnette 2012).

\section{Assessment of sperm}

Although subjective microscopic assessment of sperm motility is quick and inexpensive, it is highly subjective and often has limited repeatability (Dejarnette 2005). There are numerous computer-assisted sperm analyzer (CASA) machines that are commercially available, which provide an objective and more repeatable method of assessing sperm motility (Kathiravan et al. 2011). It is noteworthy that estimation of averages of kinematic parameters is regarded as inappropriate, as the population of sperm cells analyzed does not have a normal distribution and hence parametric statistics are not appropriate (Holt et al. 2007). In that regard, there are four categories of sperm, namely rapid, medium, slow, and static. Regardless, among the various sperm motion characteristics assessed by CASA, progressive motility and velocity parameters (e.g. VCL and VSL) and path velocity (VAP) have been associated with fertility of bull semen (Kathiravan et al. 2011).

Regarding assessment of sperm morphology, bright-field microscopy of smears stained with nigrosin-eosin were considered satisfactory for routine breeding soundness evaluations (Freneau et al. 2010). However, differential interference contrast microscopy was the preferred method of detecting major sperm defects, whereas examination of stained smears with brightfield microscopy increased the percentage of sperm with minor defects that were detected (Freneau et al. 2010). Acrosomal integrity and sperm viability are commonly measured to predict fertility. The acrosome can be stained, or assessed without staining with appropriate optical systems (e.g. Differential Interference Contrast microscopy). There are numerous live/dead stains (including nigrosin-eosin) and several stains that enable assessments to be made with flow cytometry, thereby allowing rapid and objective evaluation of large numbers of sperm. Furthermore, the hypo-osmotic swelling test (HOST) can be used to determine membrane integrity.

The sperm chromatin structure assay (SCSA) involves exposing sperm to acid hydrolysis, followed by flow cytometry to determine relative amounts of normal (double-stranded) and abnormal (single-stranded) DNA, measured as a DNA fragmentation index (\%DFI), which was negatively correlated with several bull semen end points; the strongest negative correlation was with normal sperm, with a strong positive correlation with sperm head abnormalities (D'Occhio et al. 2013). In another study (Lymberopoulos \& Khalifa 2010), bull sperm that were more susceptible to chromatin instability (acid-induced denaturation using acridine orange fluorescence) resulted in significantly lower pregnancy rates in heifers. Furthermore, fertility (non-return rate, corrected non-return rate, and calving rate) were significantly correlated with the percentage of normal sperm, which was itself negatively correlated with the percentage of DNA fragmentation (SCSA; Nagy et al. 2013). Sperm DNA fragmentation (SDF), measured with the Sperm-Halomax kit, either alone, or in combination with sperm motility, accurately identified low-fertility bulls (Karoui et al. 2012). In addition, failures of sperm chromatin condensation, due to abnormal persistence or accessibility of histones, were related to bull fertility (de Oliveira et al. 2013).

\section{Predicting fertility}

There have been numerous studies comparing sperm characteristics of bulls with varying fertility (often low- versus high-fertility, but sometimes a range). For example, for testis specific protein 
Y-linked 1 (TSPY1), which has a range of copy number (37-200 copies in cattle), the copy number was positively correlated to adjusted non-return rates (Spearman $\mathrm{r}=0.34, \mathrm{P}<0.05$ Spearman $r=0.77, P<0.01$ in two trials, respectively; Hamilton et al. 2012). However, there were no significant correlations of TSPY1 copy number with semen parameters measured. There were numerous microRNAs (small non-coding RNAs that regulate gene expression in bovine sperm), including seven that were differentially expressed between low- versus high-fertility bulls (Govindaraju et al. 2012). Holstein bulls with greater mRNA expression of cystine rich secretory protein 2 (CRISP2) and lower mRNA express of chaperonin containing T-complex protein 1, subunit 8 (CCT8) had greater fertility (Arangasamy et al. 2011). In that study, it was noteworthy that CRISP2 and CCT8 mRNA expression in sperm accounted for $95 \%$ of the variance in Holstein bull's sire conception rate scores. Sperm from low-fertility Holstein bulls had lower concentrations of transcripts for membrane and extracellular space protein locations, whereas those from high-fertility bulls had higher concentrations of transcripts for transcriptional and translational factors (Feugang et al. 2010). Based on comparative proteomic analysis of protein expression profiles of sperm from low- versus high-fertility bulls, expression of nine proteins (based on two-dimensional electrophoresis) was related to fertility $(\mathrm{P}<0.05$; Gaviraghi et al. 2010). It was noteworthy that these proteins were involved in sperm-egg interactions and cell cycle regulation.

In a study in yearling bulls, glutathione peroxidase 4 (GP4) activity, which is associated with fertility in men, was designated at high or low ( $\mathrm{n}=73$ and 19 bulls, respectively; Stradaioli et al. 2009). The former group had a greater percentage of progressively motile sperm, and a lower percentage of sperm with detached heads, abnormal midpiece, or proximal droplets. In another study, sperm from high-fertility bulls tended to more effectively penetrate artificial mucus and to have an increased ability to fertilize oocytes (both tests were conducted in vitro), but post-fertilization embryo development was not significantly affected by fertility status (AI Naib et al. 2011).

\section{Genetics and fertility}

There have been several studies regarding the effects of genotype on fertility. Semen production traits in Holstein bulls had moderate heritabilities (from 0.15 to 0.30 ) whereas some of the semen quality traits, e.g. sperm motility, had high heritabilities (close to 0.60; Druet et al. 2009). In contrast, heritabilities for nonreturn rate at $56 \mathrm{~d}$ after service and for calving per service were 0.0079 and 0.0153 , respectively (Tiezzi et al. 2013). In a comprehensive study in Holstein bulls, eight SNPs were significantly associated with sire conception rate (Peñagaricano et al. 2012). In a genotype analysis of sperm DNA from 10 low-fertility and 10 high-fertility bulls, 8,207 markers were polymorphic, of which 97 were associated with fertility $(P<0.01$; Feugang et al. 2010). In further studies to characterize these differences, it was concluded that bovine sperm integrin beta 5 protein had a role during fertilization and had potential as a marker of bull fertility. In a review of the literature to identify QTL, markers, and candidate genes, there were regions associated with fertility in each of the 30 bovine chromosomes (Fortes et al. 2013). Furthermore, across beef and dairy breeds, regions on the $\mathrm{X}$ chromosome were associated with male reproductive traits (Fortes et al. 2013). In a pathway-based association analysis in Holstein dairy cattle (1755 bulls with conception rate data and 38650 single nucleotide polymorphisms), 20 Gene Ontology (GO) terms and 1 InterPro (IP) entries were statistically associated with bull fertility (Peñagaricano et al 2013). The PRAMEY (Preferentially expressed antigen in melanoma, Y-linked) gene family is a recently identified, bovid-specific Y-linked 
gene family. The PRAMEY copy number was negatively correlated with scrotal circumference, proportion of morphologically normal sperm, and nonreturn rate (Yue et al. 2013). Furthermore, a recent report characterized an extensive literature and database search for infertility-associated candidate genes and genome loci and catalogued a total of 835 loci (Ogorevc et al. 2011). Finally, bull fertility can fluctuate over time (in the absence of an apparent cause), making it more difficult to determine the effects of genotype on bull fertility.

\section{Sperm proteins and fertility}

The relevance of seminal plasma proteins was recently reviewed (Rodriguez-Martinez et al. 2011). These proteins are relevant for sperm function, especially for interactions between sperm, various components of the female reproductive tract, the oocyte and zona pellucida. It is noteworthy that proteins act as signals and message transducers for immune responses in the female tract, modulating the immune response to sperm and affecting fertility (RodriguezMartinez et al. 2011).

Five proteins, enolase 1 (ENO1), ATP synthase $\mathrm{H}+$ transporting mitochondrial F1 complex beta subunit, apoptosis-stimulating of p53 protein 2, alpha-2-HS-glycoprotein, and phospholipid hydroperoxide glutathione peroxide, were more highly represented in high- versus low-fertility bulls, whereas voltage dependent anion channel 2 (VDAC2), ropporin-1, and ubiquinolcytochrome c reductase core protein 2 (UQCRC2), were more highly represented in low-fertility bulls (Park et al. 2012). Furthermore, among those proteins, ENO1, VDAC2, and UQCRC2 were significantly correlated with fertility in individual bulls. In one study (Byrne et al. 2012), 419 proteins were identified from a plasma membrane fraction derived from bull sperm. It was estimated that $67 \%$ of all the proteins identified were membrane associated. Many of the proteins were conserved among mammals, with roles in sperm-egg communication, capacitation and fertility. Functional pathways were associated with protein catabolism (26S proteasome complex), the chaperonin-containing TCP-1 (CCT) complex and fundamental metabolic processes (e.g. glycolysis and production of energy). In addition there were 118 proteins that were expected to be transmembrane proteins, some of which are implicated in cell adhesion, acrosomal exocytosis, vesicle transport and immunity and fertilisation events. In a study using frozen semen from 23 Holstein bulls with varying levels of fertility, eight proteins were identified as different between high- and low-fertility bulls (D'Amours et al. 2010). In that regard, CCT subunits epsilon and theta (CCT5 and CCT8), two isoforms of epididymal spermbinding protein 1 (ELSPBP1), proteasome subunit alpha type- 6 and binder of sperm protein homolog 1 (BSPH1) were more expressed in the low-fertility versus the high-fertility group, whereas adenylate kinase 1 (AK1) and phosphatidylethanolamine-binding protein 1 (PEBP1) were more expressed in the high-fertility group. Based on linear regression, CCT5 and AK1 explained $64 \%(P<0.001)$ of the fertility scores.

\section{Conclusions}

Testicular function and fertility in bulls remain critically important, with many questions yet to be answered. For example, recent studies have highlighted the importance of nutrition on development, and there are indications that the effects of hyperthermia on sperm quality might not be due to hypoxia. In addition, current methods for prediction of fertility are generally more effective for identifying bulls with low fertility, but are much less effective for predicting relatively fertility among bulls that are above minimum standards. Therefore, there is still much 
work to be done. On a positive note, new and emerging tools in cellular and molecular biology have created much new knowledge and insights, and should be valuable in ongoing efforts to understand, and improve, testicular function and fertility.

\section{References}

Al Naib A, Hanrahan JP, Lonergan P \& Fair S 2011. In vitro assessment of sperm from bulls of high and low field fertility. Theriogenology 76 161-167.

Amann RP \& DeJarnette JM 2012. Impact of genomic selection of $\mathrm{Al}$ dairy sires on their likely utilization and methods to estimate fertility: a paradigm shift. Theriogenology 77 795-817.

Arangasamy A, Kasimanickam VR, DeJarnette JM \& Kasimanickam RK 2011. Association of CRISP2, CCT8, PEBP1 mRNA abundance in sperm and sire conception rate in Holstein bulls. Theriogenology 76 570-577.

Barros CMQ, Oba E, Brito LFC, Cook RB, Coulter GH, Groves G, Olson M \& Kastelic JP 1999. Avaliação do fluxo sanguineo e do oxigenio testicular em touros Aberdeen Angus [Testicular blood flow and oxygen evaluation in Aberdeen Angus bulls]. Revista Brasileira de Reprodução Animal 23 218-220.

Barth AD, Brito LFC \& Kastelic JP 2008. The effect of nutrition on sexual development of bulls. Theriogenology 70 485-495.

Bratton RW, Musgrave SD, Dunn HO \& Foote RH 1959. Causes and prevention of reproductive failure in dairy cattle: II. Influence of underfeeding and overfeeding from birth to 80 weeks of age on growth, sexual development, and semen production in Holstein bulls. Bulletin 940. New York State College of Agriculture, Ithaca NY, $45 \mathrm{pp}$.

Brito LFC, Barth AD, Wilde RE \& Kastelic JP 2012. Effect of growth rate from 6 to 16 months of age on sexual development and reproductive function in beef bulls. Theriogenology 77 1398-1405.

Byrne K, Leahy T, McCulloch R, Colgrave ML \& Holland MK 2012. Comprehensive mapping of the bull sperm surface proteome. Proteomics 12 3559-3579.

Cook RB, Coulter GH \& Kastelic JP 1994. The testicular vascular cone, scrotal thermoregulation, and their relationship to sperm production and seminal quality in beef bulls. Theriogenology 41 653-671.

Coulter GH \& Kastelic JP 1999. Management programs for developing bulls. In Current Veterinary Therapy-Food Animal Practice 4., pp 127-136. Eds JL Howard \& R Smith. Philadelphia:W.B. Saunders Co.

D'Amours O, Frenette G, Fortier M, Leclerc P \& Sullivan R 2010. Proteomic comparison of detergent-extracted sperm proteins from bulls with different fertility indexes. Reproduction 13 545-556.

DeJarnette JM 2005. The effect of semen quality on reproductive efficiency. Veterinary Clinics of North America Food Animal Practice 21 409-418.

de Oliveira RV, Dogan S, Belser LE, Kaya A, Topper E, Moura A, Thibaudeau G \& Memili E 2013. Molecular morphology and function of bull spermatozoa linked to histones and associated with fertility. Reproduction 146 263-72.

Druet T, Fritz S, Sellem E, Basso B, Gérard O, Salas-Cortes L, Humblot P, Druart X \& Eggen A 2009. Estimation of genetic parameters and genome scan for 15 semen characteristics traits of Holstein bulls. Journal of Animal Breeding and Genetics 126 269-277.

D'Occhio MJ, Hengstberger KJ, Tutt D, Holroyd RG, Fordyce G, Boe-Hansen GB \& Johnston SD 2013. Sperm chromatin in beef bulls in tropical environments. Theriogenology 79 946-952.

Feugang JM, Rodriguez-Osorio N, Kaya A, Wang $\mathbf{H}$, Page G, Ostermeier GC, Topper EK \& Memili E 2010. Transcriptome analysis of bull spermatozoa: implications for male fertility. Reproduction Biomed Online 21 312-324.

Flowers, WF 2013. Sperm characteristics that limit success of fertilization. Journal of Animal Science 91 30223029.

Fortes MR, Reverter A, Kelly M, McCulloch R \& Lehnert SA 2013 Genome-wide association study for inhibin, luteinizing hormone, insulin-like growth factor 1, testicular size and semen traits in bovine species. Andrology 1 644-650

Freneau GE, Chenoweth PJ, Ellis R \& Rupp G 2010. Sperm morphology of beef bulls evaluated by two different methods. Animal Reproduction Science 118 176-81.

Gaviraghi A, Deriu F, Soggiu A, Galli A, Bonacina C, Bonizzi L \& Roncada P 2010. Proteomics to investigate fertility in bulls. Veterinary Research Communications 34 Supplement 1 33-36.

Govindaraju A, Uzun A, Robertson L, Atli MO, Kaya A, Topper E, Crate EA, Padbury J, Perkins A \& Memili E 2012. Dynamics of microRNAs in bull spermatozoa. Reproductive Biology Endocrinology 1082.

Hamilton CK, Verduzco-Gómez AR, Favetta LA, Blondin P \& King WA 2012. Testis-specific protein Y-encoded copy number is correlated to its expression and the field fertility of Canadian Holstein bulls. Sexual Development 6 231-239.

Higdon HL 3rd, Spitzer JC, Hopkins FM \& Bridges Jr WC. 2000. Outcomes of breeding soundness evaluation of 2898 yearling bulls subjected to different classification systems. Theriogenology 53 1321-1332.

Holt WV, O' Brien J \& Abaigar T 2007. Applications and interpretation of computer assisted sperm analysis and sperm sorting methods in assisted breeding and comparative research. Reproduction Fertility and Development 19 709-718.

Karoui S, Díaz C, González-Marín C, Amenabar ME, Serrano M, Ugarte E, Gosálvez J, Roy R, LópezFernández C \& Carabaño MJ 2012. Is sperm DNA 
fragmentation a good marker for field AI bull fertility? Journal of Animal Science 90 2437-2449.

Kastelic, JP, Coulter GH \& Cook RB 1995. Scrotal surface, subcutaneous, intratesticular, and intraepididymal temperatures in bulls. Theriogenology 44 147-152.

Kastelic, JP, Coulter GH \& Cook RB 1996. Contribution of the scrotum and testes to scrotal and testicular thermoregulation in bulls and rams. Journal of Reproduction and Fertility 108 81-85.

Kastelic, JP, Cook RB \& Coulter GH 1997. Contribution of the scrotum, testes, and testicular artery to scrotal/ testicular thermoregulation in bulls at two ambient temperatures. Animal Reproduction Science 45 255-261.

Kastelic JP \& Thundathil J 2008. Breeding soundness evaluation and semen analysis for predicting bull fertility. Reproduction in Domestic Animals 43 Supplement 2 368-373.

Kastelic, JP, Wilde R, Bielli A, Genovese P, BilodeauGoeseels P \& Thundathil J 2008. Hyperthermia is more important than hypoxia as a cause of $d$ i s r u p t e d spermatogenesis. Reproduction in Domestic Animals 43 Supplement 3166.

Kastelic JP, Thundathil JC \& Brito LFC 2012. Bull BSE and semen analysis for predicting bull fertility. Clinical Theriogenologyb 277-287.

Kastelic, JP 2014. Thermoregulation of the testes. In: Hopper RM, editor. Bovine Reproduction. Hoboken: WileyBlackwell (In Press).

Kathiravan P, Kalatharan J, Karthikeya G, Rengarajan K \& Kadirvel G 2011. Objective sperm motion analysis to assess dairy bull fertility using computer-aided system - a review. Reproduction in Domestic Animals 46 165-172.

Kennedy SP, Spitzer JC, Hopkins FM, Higdon III HL \& Bridges Jr WC 2002. Breeding soundness evaluations of 3648 yearling beef bulls using the 1993 Society for Theriogenology guidelines. Theriogenology 58 947-961.

Lunstra DD, Gregory KE \& Cundiff LV 1988. Heritability estimates and adjustment factors for the effects of bull age and age of dam on yearling testicular size in breeds of bulls. Theriogenology 30 127-136.

Lymberopoulos AG \& Khalifa TA 2010. Sperm chromatin stability during in vitro manipulation of beef bull semen. Reproduction in Domestic Animals 45 307-314.

Nagy S, Johannisson A, Wahlsten T, ljäs R, Andersson M \& Rodríguez-Martínez H 2013. Sperm chromatin structure and sperm morphology: their association with fertility in Al-dairy Ayrshire sires. Theriogenology 79 1153-1161.

Ogorevc J, Dovc P \& Kunej T 2011. Comparative genomics approach to identify candidate genetic loci for male fertility. Reproduction in Domestic Animals 46 229-239.

Park YJ, Kwon WS, Oh SA \& Pang MG 2012. Fertilityrelated proteomic profiling bull spermatozoa separated by percoll. Journal of Proteome Research 11 4162-4168.

Peñagaricano F, Weigel KA \& Khatib H 2012. Genomewide association study identifies candidate markers for bull fertility in Holstein dairy cattle. Animal Genetics 43 Supplement 1 65-71.

Peñagaricano F, Weigel KA, Rosa GJ \& Khatib H 2013. Inferring quantitative trait pathways associated with bull fertility from a genome-wide association study. Frontiers in Genetics 3307.

Rodríguez-Martínez H, Kvist U, Ernerudh J, Sanz L \& Calvete JJ 2011. Seminal plasma proteins: what role do they play? American Journal of Reproductive Immunology $\mathbf{6 6}$ Supplement 1 11-22.

Rodriguez-Martinez H 2012.Assisted reproductive techniques for cattle breeding in developing countries: a critical appraisal of their value and limitations. Reproduction in Domestic Animals 47 Supplement 1 21-26.

Stradaioli G, Sylla L, Monaci M \& Maiorino M 2009. Phospholipid hydroperoxide glutathione peroxidase in bull spermatozoa provides a unique marker in the quest for semen quality analysis. Theriogenology 72 91-98.

Tiezzi F, Maltecca C, Penasa M, Cecchinato A \& Bittante G 2013 Short communication: Genetic analysis of dairy bull fertility from field data of Brown Swiss cattle. Journal of Dairy Science 96 7325-7328.

Waldner CL, Kennedy RI \& Palmer CW 2010. A description of the findings from bull breeding soundness evaluations and their association with pregnancy outcomes in a study of western Canadian beef herds. Theriogenology 74 871-883.

Yue XP, Chang TC, Dejarnette JM, Marshall CE, Lei CZ \& Liu WS 2013. Copy number variation of PRAMEY across breeds and its association with male fertility in Holstein sires. Journal of Dairy Science 96 8024-8034. 